\title{
DUAS JOIAS DO MUSEU NACIONAL: UMA APRESENTAÇÃO A “UM MANTO REAL DE HAWAII" DE EDGARD ROQUETTE-PINTO ${ }^{1}$
}

\author{
Edmundo Pereira ${ }^{1}$ \\ https://orcid.org/0000-0002-9219-3537
}

${ }^{1}$ Universidade Federal do Rio de Janeiro, Programa de Pós-graduação em Antropologia Social, Museu Nacional,

Editoria de Mana, Rio de Janeiro/RJ, Brasil

Dentre as coleções etnográficas do Museu Nacional/UFRJ, tinham destaque, antes do incêndio de setembro de 2018, as da Oceania e noroeste norte-americano por sua antiguidade e excepcionalidade. ${ }^{2}$ No complexo expográfico da Etnologia, a galeria Culturas do Pacífico reunia objetos icônicos de regiões socioculturais variadas (Polinésia, Melanésia e Noroeste norte-americano) e de determinados períodos históricos (entre 1820 e o final do século XIX), notadamente marcados por guerras intertribais e de conquista imperial europeia. Não sem razão, boa parte do conjunto de objetos exibidos, em suas sete vitrines, se referia à guerra e à chefia: clavas de Fiji, Samoa, Nova Zelândia e llhas Marquesas; bumerangues da Austrália, lanças da Nova Guiné, enxós e remos cerimoniais das Ilhas Cook, Nova Zelândia e Hawaii. ${ }^{3}$ No centro da galeria, peças raras do acervo, um manto acompanhado de colar de penas do Hawaii, datado de 1824, presente dos reis do arquipélago, em seu encontro com o imperador Pedro I e a imperatriz Leopoldina em passagem pelo Rio de Janeiro imperial brasileiro das primeiras décadas do século XIX. 
A transação e a circulação de tais objetos, no século XIX dos Mares do sul, período de primeiros contatos e formação de modos de relação entre povos ilhotas e europeus e norte-americanos, se deu inicialmente em circuitos restritos e ritualizados, marcados por cerimonial e protocolo, entre representantes de reinos ultramarinos e de povos locais (Thomas 2010; Thomas et al. 2016). Do ponto de vista da literatura dedicada às condições de colecionamento etnográfico, ${ }^{4}$ a circulação de objetos em regimes de presentes entre autoridades pode ser entendida segundo certa "cultura diplomática" (Behrens-Abouself 2014), rastreável historicamente desde pelo menos o século XIII na relação entre europeus, árabes e asiáticos. Além disso, para o caso da coleção das Ilhas Sandwich (termo colonial para o arquipélago havaiano), mandadas conservar pelo imperador Pedro I no Museu Nacional (então, Museu Real), estamos diante de um outro sentido nos movimentos em curso do período, ponto de revisões historiográficas recentes: o da circulação de pessoas, de ilhotas, em especial chefes, cabeças de clã, reis e nobres na mediação de conflitos e articulação de alianças no enredamento da guerra e do comércio (Thomas 1995, 2010). Alguns destes entraram em navios baleeiros ou de expedições científicas para conhecer em maior extensão seus vizinhos, outros chegaram à Europa, às Américas e à Ásia.

No caso havaiano, desde os primeiros contatos entre ilhotas e ingleses, os encontros foram marcados pela troca cerimonial de presentes, no caso da nobreza ilhota, mantos e capas de penas ('Ahu'ula) de pássaros de algumas das ilhas do arquipélago. Atualmente, encontramos cerca de 170 exemplares de mantos e capas espalhados por museus do hemisfério norte (Arbeit 2011). Sua excepcionalidade se evidencia pela expertise dos saberes neles concentrados numa extensa cadeia operatória que unia ilhas, em especial a caça de pássaros e a acumulação de penas e plumas (Thomas 2010; Walters 2006), e pelo seu sentido sagrado e de proteção, referido à posição política da nobreza e ao mana neles reunido, que fazia dos mantos "armaduras da divindade" (Thomas 2010). Desde o primeiro encontro com os ingleses, em 1778, quando o almirante James
Cook alcançou o arquipélago na $3^{\mathrm{a}}$ viagem de sua frota, mantos e capas de penas foram oferecidos em sinal de aliança e cooperação e sua produção se intensificou nas décadas seguintes, em especial para este novo circuito de trocas, de exemplares novos e desprovidos de mana (Thomas 2010; Arbeit 2011; Kaeppler 1978).

Com a crise e o agravamento de conflitos advindos com a morte de Kamehameha I (Thomas 2010; Kuykendall 1938; Kahananui 1984), cujo reinado (1790-1819) produzira transformações políticas propulsionadas pela pólvora e pela construção de grandes navios, seu filho, Liholiho (Kamehameha II), organiza uma pequena comitiva para viajar para a Inglaterra no esforço de consolidar uma aliança para a defesa do arquipélago em face de investidas de norte-americanos e russos pelo controle desse ponto estratégico no trânsito transcontinental do Pacífico. Na bagagem, foram levados pelos menos cinco mantos e capas, que foram presenteados entre a saída do Hawaii e a chegada e recepção na Inglaterra. O primeiro presente, uma capa, foi dado ao capitão no navio baleeiro inglês L'Aigle, Valentine Starbuck, confeccionado para a viagem. O segundo, outra capa, também de confecção no século XIX, para outro oficial do navio. Apenas na primeira grande parada da viagem, em 1824, no Rio de Janeiro, o rei presenteia outro rei (Pedro I) com um manto, dos mais preciosos e raros que levava, provavelmente mais antigo se tomarmos o tipo de composição gráfica que apresentava (Kaeppler 1978). Do ponto de vista da família real havaiana: "Foi a primeira vez que Liholiho conheceu um irmão soberano" (Judd 1976:164). Outras duas capas foram presenteadas a funcionários do Foreign Office na chegada à Inglaterra. Pouco depois, Kamehameha II faleceu, em solo inglês, sem chegar a ser recebido pela nobreza britânica. Sobre o encontro entre soberanos em terras brasileiras, reunimos os seguintes elementos das narrativas orais transmitidas dentro da família real havaiana (Judd 1976) dos eventos de 15 de fevereiro de 1824 no Rio de Janeiro: A sala do trono estava cheia, da nobreza ao corpo diplomático. Intérpretes trabalhavam de ambos os lados. D. Pedro recebeu a comitiva de pé e se encaminhou para Kamehameha II. Saudaram-se. 
O rei Liholiho murmurou: Aloha. Seguiu-se uma troca de presentes. O imperador ofereceu uma espada, Lihohilo ofereceu um ahuula (manto real de penas) e um kahili (cetro de penas). O manto muito agrada "porque era um antigo costume brasileiro usar mantos de penas na vestimenta das coroações dos imperadores" (Judd 1976:165). Quase cem anos depois de tais eventos, Edgard Roquette-Pinto, médico e antropólogo, desde 1905 trabalhando no Museu Nacional como professor assistente para a 4 a Seção de Antropologia, Etnografia e Arqueologia (Veloso 2019), publica um pequeno estudo sobre o manto real havaiano no volume 1 do Boletim do Museu Nacional (1923), na série dedicada à Antropologia, consagrado na documentação de guarda e tombamento da instituição como manto owhyeen (termo colonial para se referir aos nativos do arquipélago). Recuperando dimensões materiais, técnicas e simbólicas do manto e de sua condição de aquisição, que hoje seriam correlatas aos estudos de vida social das coisas ou história dos objetos (Appadurai 2008; Findlen 2013), classifica patrimonialmente a peça como "uma das joias do Museu Nacional". Tomada sua produção desde o final da década de 1910, sobretudo a partir da publicação e da repercussão do livro Rondônia (1917), o texto tanto pode ser entendido como a extensão de suas preocupações etnográficas para além do horizonte indígena, no período materializadas na atenção à coleções como as sertanejas e a estrangeiras (Santos 2019), quanto como reflexo do investimento curatorial e de divulgação científica em curso na $4^{a}$ Seção (Faria 1959; Moreira et al. 2008; Veloso 2019; Santos 2019, 2020).

Por essa época, o processo de catalogação das coleções etnográficas, iniciado em 1906 por Roquette-Pinto e equipe, estava avançado
(Veloso 2019). No volume 3 do Catálogo das Coleções de Antropologia e Etnografia, a coleção das Ilhas Sandwich, oferta de Pedro I ao Museu Nacional (então Museu Real) aparece composta por sete peças, algumas dessas excepcionais no horizonte das coleções da Oceania abrigadas por museus ao redor do mundo, que tanto retratam os valores e os conhecimentos havaianos quanto o cerimonialismo da ocasião. ${ }^{5}$ Além das peças já mencionadas, ressaltamos ainda dois remos cerimoniais, com intrincado ornamental em entalhe, e um bastão de presa de narval (Monodon monóceros).

Assim como a joia de que tenta recuperar parte da vida social, passados quase cem anos da publicação do texto, ${ }^{6}$ a peça científica ora republicada é também joia, ponto de inflexão e desenvolvimento histórico de projetos científicos, resultado tanto de pesquisa em fontes documentais e literárias quanto da composição de histórias das coleções que circulam nos corredores das instituições museais e da cooperação entre museus e curadorias. Logo antes do incêndio de 2018, o original do trabalho de Roquette-Pinto foi encontrado na Seção de Memória e Arquivo (Semear) do Museu Nacional, ${ }^{7}$ durante pesquisa sobre as condições de colecionamento e curadoria de algumas das coleções abrigadas na galeria Culturas do Pacífico. Consumido pelas chamas, ficou seu registro fotográfico. Editorialmente, optamos por respeitar as normas ortográficas do período em que foi datilografado. Com sua republicação neste momento, tanto esperamos seguir a mesma trilha da pesquisa e divulgação de algumas das joias do Museu Nacional quanto contribuir com o processo de reconstrução museal em curso com a documentação de algumas de suas coleções desaparecidas. ${ }^{8}$ 
Foto 1: Primeira página do original encontrado no Semear/Museu Nacional

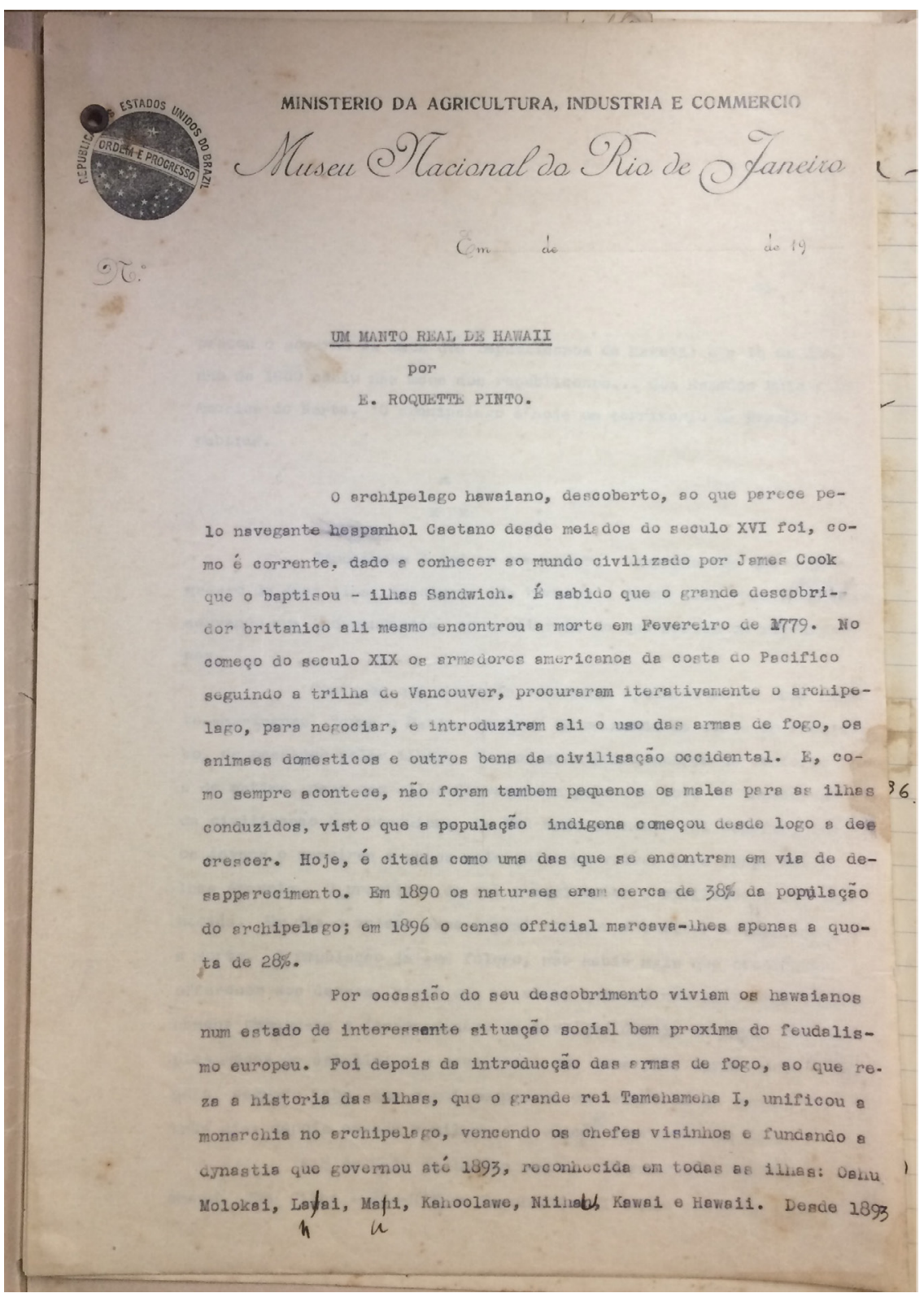




\section{UM MANTO REAL DE HAWAII \\ por \\ E. Roquette-Pinto}

O archipelago hawaiano, descoberto, ao que parece pelo navegante hespanhol Caetano desde meiados do seculo XVI foi, como é corrente, dado a conhecer ao mundo civilizado por James Cook que o baptisou — ilhas Sandwich. É sabido que o grande descobridor britanico ali mesmo encontrou a morte em Fevereiro de 1779. No começo do seculo XIX os arredores americanos da costa do Pacifico seguindo a trilha de Vancouver, procuraram iterativamente o archipelago, para negociar, e introduziram ali uso das armas de fogo, os animaes domesticos e outros bens da civilisação occidental. E, como sempre acontece, não foram tambem pequenos os males para as ilhas conduzidos, visto que a população indigena começou desde logo a decrescer. Hoje, é citada como uma das que se encontram em via de desapparecimento. Em 1890 os naturaes eram cerca de 38\% da população do archipelago; em 1896 o censo official marcava-lhes apenas a quota de $28 \%$.

Por ocasião do seu descobrimento viviam os hawaianos num estado de interessante situação social bem proxima do feudalismo europeu. Foi depois da introdução das armas de fogo, ao que reza a historia das ilhas, que o grande rei Tamehameha I, unificou a monarchia no archipelago, vencendo os chefes visinhos e fundando a dynastia que governou até 1893, reconhecida em todas as ilhas: Oahu, Molokai, Lanai, Maui, Kahoolawe, Niihau, Kawai e Hawaii. Desde 1893 passou o governo às mãos dos republicanos de Hawaii; e a 14 de Junho de 1900 cahiu nas mãos dos republicanos... dos Estados Unidos da America do Norte. O archipelago é hoje um território da grande republica.

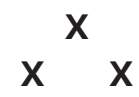

Tamehameha I foi um precursor. Comprehendeu que o progresso de suas ilhas precisava dos brancos e desde cedo resolveu, conservando sua independencia, aproveitar-se do que sabiam os alienigenas.

Conta-se que sem mais ceremonia apoderou-se de dois norte-americanos, Young e Davis, mestres de um navio da costa do Pacifico, de passagem pelas ilhas. Cercou seus prisioneiros de conforto e de estima, para que elles derramassem pelo seu povo os thesouros da civilisação que possuiam. De tal modo se houve rei esperto, que os jovens o serviram e nunca mais quizeram 
volver para longe das ilhas amaveis. O prestigio do rei conquistador e civilisador foi sem medida. Um dia o vulcão Unna-Ararai começou a vomitar a desgraça e a morte. A população já sem folego, não sabia mais que sacrificio offerecer aos deuses, visto que as vidas humanas não bastavam. Tamehameha chegou-se e lançou dentro da lava que descia em fogo, uma simples mecha de cabello; e o sacrificio dos seus fios negros protegidos pelo sagrado

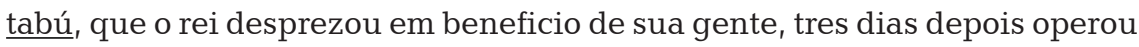
milagre: o vulcão adormeceu de novo.

A 8 de maio de 1819 o grande rei morria, divinisado e amado. Seu filho - Rio-Rio ou Tamehameha II tomou conta do archipelago. Foi tambem um rei sabio. Pertenceu-lhe o manto de pennas que é uma das joias do Museu Nacional do Rio de Janeiro (Fig. 1). ${ }^{9}$

Fig. 1: Manto do rei Tamehameha (Coll. Do Museu Nacional)

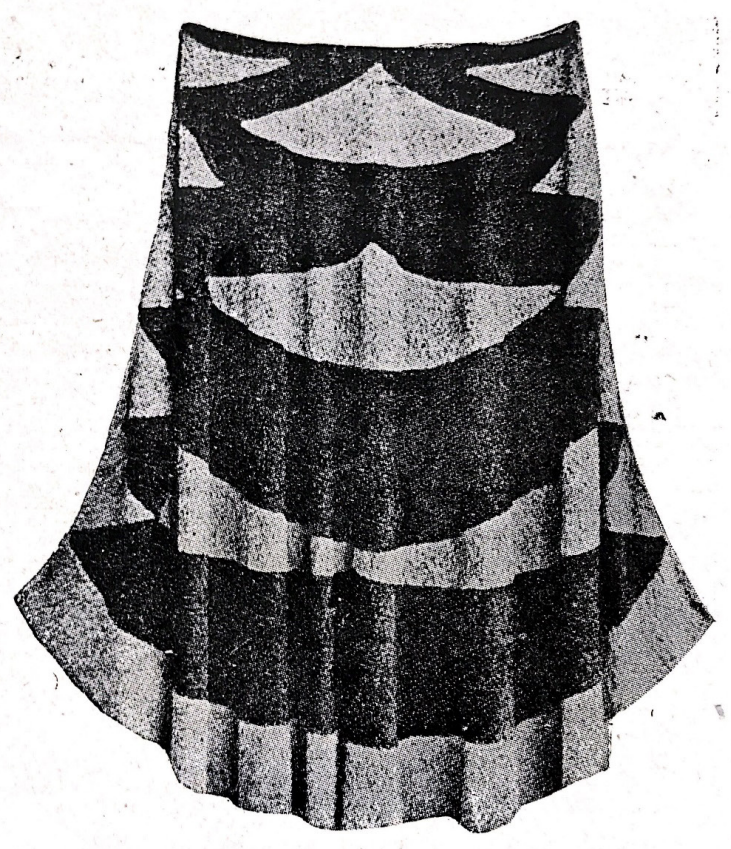




\section{$x$ \\ $\mathrm{X} \quad \mathrm{X}$}

Os mantos de pennas de Hawaii constituem peças valiosissimas de que se acham enriquecidos alguns museus do Mundo.

William T. Brigham, director do Bernice Pauahi Bishop Museum, de Honolulu, conseguiu examinar quasi todos os que se encontram naquelles institutos, não tendo tido occasião de ver o nosso, talvez o mais interessante, sinão o mais rico, visto que tem uma historia excepcionalmente bem documentada. Brigham diz ter conseguido colleccionar até 1898 aquarellas de 17 destas peças.

O interesse que os mantos dos Hawaianos despertam, não provam apenas de sua belleza, do admiravel acabamento do seu trabalho textil e ornamental.

Ao que se affirma, as especies ornithologicas de que foram arrancadas as pennas de taes vestes acham-se hoje, praticamente extinctas. A ilha de Modu-Manu, que pertence ao archipelago, era a preferida pelos caçadores de pennas. Os inglezes, talvez por isso mesmo, chamaram-na ilha de Bird.

As aves fornecedoras de plumagem dos mantos reaes eram de pequeno tamanho ao que dizem os antigos navegantes e pertenciam a familia Souimanga, vulgarmente: "Papa-mel".

Pelos nomes locaes, umas chamavam-se iwii e outras: oo. Em geral os mantos são tecidos em fibras de palmeiras de malhas, quadrangulares (net-work dos inglezes), em cada nó fixam-se, em pequenos pinceis, algumas pennas.

Quasi sempre o fundo é constituído de pennas amarellas; sobre elle destacam-se os motivos proprios.

O manto do rei Rio-Rio, no Museu Nacional do Rio de Janeiro, ( ${ }^{\circ} 6.825$, da Collecção Ethnographica) apresenta motivos triangulares amarellos, separados por faixas vermelhas.

Pesa 1.870 gram. Tem as dimensões expressas no eskema da fig. 2: 1,47 $\mathrm{m}$ de altura, 2,25 $\mathrm{m}$ de largura e 0,72 ao nivel do collo. O desenho da fig. 3 mostra a malha do trançado das fibras, em proporções bastante augmentadas. 


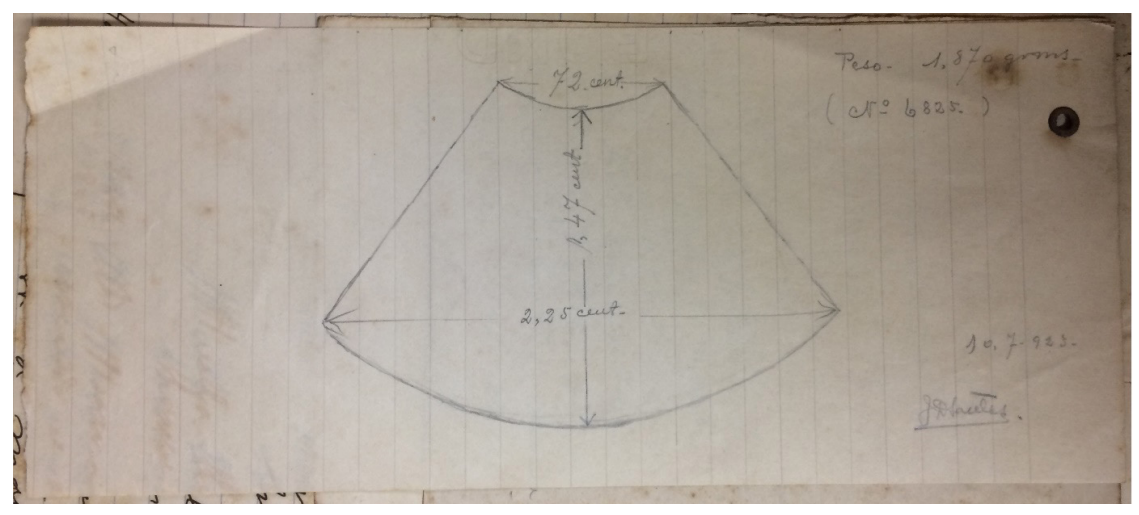

Fig. 3: Desenho eschematico do trançado a que se prendem as pennas do manto

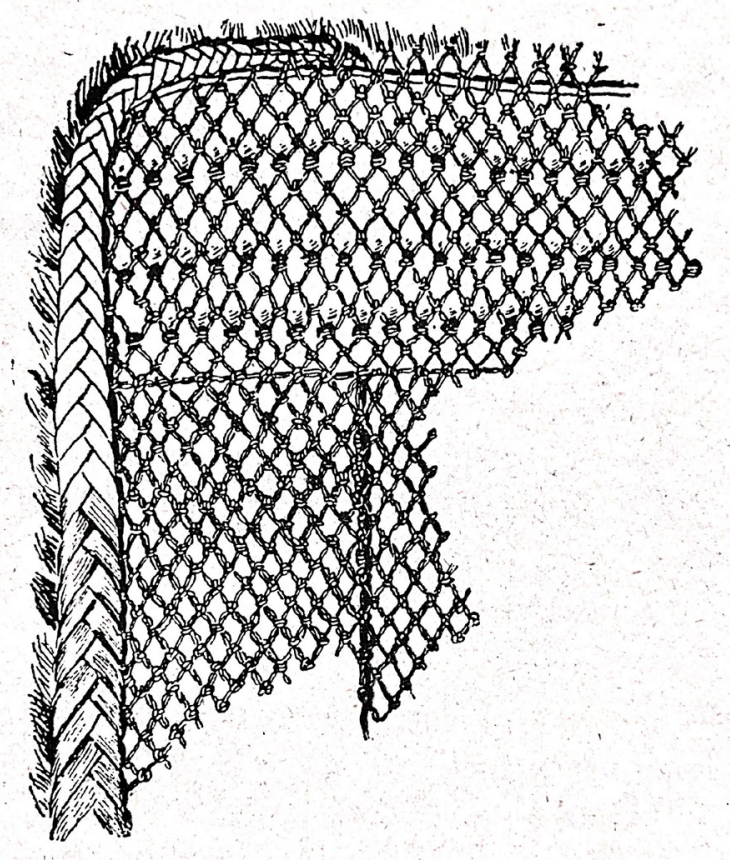


Ao que diz o director do Museu de Honolulu, o trançado local mais parecido com os que se encontram no Brasil, no material feito de pennas, são as fieiras, que nas ilhas recebem o nome de $\underline{\text { lei. }}$.

Este trançado do manto, comparado com alguns exemplares da nossa collecção brasiliense, approxima-se bastante, pelo feitio, salvo as dimensões das malhas, do trançado das coifas de pennas fabricadas pelos indios Karajás, do rio Araguaia. (Hari-Lori dos Karajás, Collecção do Museu Nacional, $\left.n^{\circ} 2477\right)$.

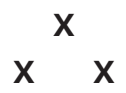

Rio-Rio ou Tamehamehá II não foi, nem a historia das ilhas assim o exigia, um conquistador como seu pai.

Homem intelligente e emprehendedor, progressista, marcou sua breve passagem pelo trono realizando reformas sociaes de alto alcance. Influenciado pelos missionarios inglezes, especialmente por Mr. Ellis, Rio-Rio começou convocando um congresso de notaveis para abolir os sacrificios humanos e a velha idolatria insulana. "Que mal podem fazer os nossos deuses?" Perguntara-lhe sua mãe, ao que informam os chronistas. E, nessa mesma questão, vê-se bem como o prestigio da antiga religião tinha cahido...

No seu reinado, imprimiu-se o primeiro livro em Hawaii.

Arago nas "Recordações um cégo" consagra algumas linhas, como sempre, escriptas mais para divertir que para informar, ao referido rei, que elle visitou.

Entre muitos factos anedocticos, refere que a mulher favorita do soberano tinha tatuado, na lingua, os caracteres do nome real...

Sedento do progresso para suas ilhas, Rio-Rio resolveu ir à Europa visitar, especialmente, um rei que moravam em outro archipelago, mas que era senhor de grande parte do mundo: George IV da Inglaterra.

Deixando as ilhas entregues a Korai-Moku, Tamehamehá II partiu a bordo do Eaglé, a 27 de Novembro de 1823.

Em sua companhia seguiram a rainha Kaméa-Marú, o Governador Boki, da ilha Oahu, e o francez Rives que tinha chegado a Hawaii como grumete havia algum tempo, e fizera-se medico aclamado no archipelago. 


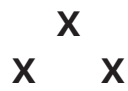

Quarta-feira, 18 de Fevereiro de 1824 publicava o "Diario do Governo", no Rio de Janeiro:

"Noticias maritimas. Entradas":

Dia 16 - Ilhas de Sandwich; 97 dias; G. Ing. Le Eagle, M. Valentine Starbuck. Equipagem 34, carga de azeite, segue para Londres: passageiros Rihoriho, Rei das Ilhas de Sandwich com sua mulher e 10 pessoas de sua cometiva, o qual vae visitar o Rei de Gran-Bretanha."

Alguns dias depois o jornal official do nascente Imperio do Brasil publicava ainda a respeito do rei de Hawaii:

Imperio do Brasil:

Diario do Governo $n^{\circ} 48$ - segunda-feira - 1 de Março de 1824 Rio de Janeiro.

No dia 27 do corrente, pelas 11 horas da manhã com grande Audiencia de S. M. I., onde assisti a Imperatriz, e a Serenissima Princeza Imperial, se apresentarão o Rei de Sandwich com sua espoza que aportarão a esta Côrte, sendo o seu destino hirem comprimentar El-Rei da Grã-Bretanha. SS. M.M. I.I. receberão com devidas demonstrações as Altas Personagens, que lhes forão presentes, e depois de lhes mostrarem os testemunhos de Sua Gratidão pela visita, recebeu o Rei das mãos de S. M. I. huma rica espada, e Sua Espoza hum anel de brilhantes de grande preço.

No mesmo dia, convidados pelo Consul Inglez residente nesta Côrte, foram a hum jantar, o qual durou até à noute, a que se seguiram alguns outros festejos, em signal do prazer que causarão os Augustos Hospedes. 


\section{$x^{X} x$}

Nada se diz dos presentes com que as majestades polynesias brindaram Pedro I. Mas no archivo do Museu Nacional, actualmente organizado pelo operoso Snr. Leopoldo Pimentel Barbosa, encontra-se o original do officio por meio do qual foi recolhido ao Museu o manto do Rio-Rio ou Tamehamehá II juntamente com um collar de pennas, offerta da rainha que se acha tambem em nossa collecção sob o numero de 6.824:

$$
\begin{gathered}
1824 \text { - Março } 15 \text { - Pasta } 1 . \\
\text { Doc. n } 30 \\
\text { Museu Nacional. }
\end{gathered}
$$

Manda sua Majestade o Imperador, pela Secretaria dos Negocios Estrangeiros, remetter com esta ao Director do Museu Nacional desta Côrte, para serem nelle conservados, o manto Owhyeen que o Rei desta Ilha, Tamehamerá $2^{\circ}$ offerecêra quando se achou nesta Côrte, e bem assim um colar de plumas offerecido igualmente pela Rainha Tameha-Malú.

Paço, 15 de Março de 1824.

Luiz. J. de Carv. Melo

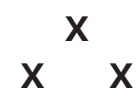

O Eagle com a carga real chegou a Portsmouth a 31 de Maio de 1824. Os reis de Sandwich não encontraram nas ilhas o mesmo agasalho que lhes dispensou Pedro I do Brasil. Pediram audiencia a George IV. O protocollo da corte brithanica foi moroso. Rio-Rio teve tempo de morrer, quasi ao mesmo tempo que sua amada esposa. A noticia despertou a corte de Londres. George IV mandou vir a sua presença Boki e os outros personagens hawaianos; cumulou-os de presentes, para que olvidassem assim o tempo em que foram todos, com o seu rei, quasi desprezados e ordenou que a fragata Blonde, ao mando do Capitão Byron reconduzisse às ilhas longinquas os restos reaes e a comitiva de Rio-Rio.

Em 1825 chegava o capitão Byron ao archipelago e plantava, no local em que James Cook fôra morto, um marco votivo, entregando à terra da patria o antigo Senhor das Ilhas. 


\section{Notas}

1 Agradecimento: aos colegas da Seção de Memória e Arquivo (Semear) e do Setor de Etnologia e Etnografia (SEE) do Museu Nacional, pela dedicação, atenção e o debate qualificado sobre as condições de registro e entrada dos materiais documentais e etnográficos reunidos.

2 No volume III do catálogo geral, ocupam as entradas que vão de 6.583 a 6.828, totalizando 246 registros de objetos provenientes de povos da Austrália, Melanésia, Polinésia e noroeste-norte-americano.

3 Seção de Museologia (Semu), 2006.

4 Veja-se, p.ex., Thomas (1991, 2010); O'Hanlon e Welsh (2000); Bennett et al. (2017); Cohn (1996.

5 Para um quadro comparativo dos mantos reunidos por museus ao redor do mundo, veja-se: Arbeit (2011); Thomas (1995).

6 O trabalho seria republicado em 1927, na coletânea de ensaios Seixos Rolados que abrange parte da produção do antropólogo nas décadas de 1910-1920.

7 Fundo Antropologia, caixa 12.

8 Em 2018, o acervo do Fundo Bertha Lutz foi eleito pelo Comitê Nacional do Programa Memória do Mundo da Unesco como "patrimônio da humanidade". A parte do fundo abrigada pelo Museu Nacional, por conta de seu desaparecimento no incêndio de setembro daquele ano, foi nomeada na categoria "patrimônio documental desaparecido ou acervo perdido", política do programa de atenção às "memórias perdidas" que objetiva registrar acervos raros que foram destruídos por catástrofes ou acidentes (Serejo, 2020).

9 Nota da Editoria: Para uma imagem contemporânea do manto, consulte-se: https://museunacional.ufrj.br/dir/exposicoes/etnologia/culturas_do_pacifico.html 


\section{Referências bibliográficas}

APPADURAI, Arjun (org.). 2008. A vida social das coisas. As mercadorias sob uma perspectiva cultural. Niterói: Eduff.

ARBEIT, Wendy. 2011. Links to the past. The work of early Hawaiian artisans. Honolulu: University of Hawaii Press.

BEHRENS-ABOUSEIF, Doris. 2014. Practising diplomacy in the Mamluk sultanate. Gifts and material culture in the Medieval Islamic World. London: I. B. Tauris.

BENNETT, Tony; CAMERON, Fiona; DIAS, Nélia; DIBLEY, Ben; HARRISON, Rodney; JACKNIS, Ira \& MCCARTHY, Conal. 2017. Collecting, Ordering, Governing. Anthropology, Museums and Liberal Government. Durham: Duke University Press.

COHN, Bernard. 1996. Colonialism and its forms of Knowledge. The British India. New Jersey: Princeton University Press.

FARIA, Luis de Castro. 1959. A contribuiÇão de E. Roquette-Pinto para a Antropologia Brasileira. Rio de Janeiro: Museu Nacional.

FINDLEN, Paula (ed.). 2013. Early modern things. Objects and their histories, 1500-1800. New York: Routledge.

JUDD, Walter. 1976. Let us go. The narrative of Kamehameha II king of the Hawaiian islands 1819-1824. Honolulu: Topgallant Publishing.

KAEPPLER, Adrienne L. 1978. "L'Aigle and HMS "Blonde". The use of history in the study of ethnography". Hawaiian Journal of History, 12:28-44.

KAHANANUI, Dorothy. 1984. Ka Moolelo Hawaii. Hawai: University of Hawaii.
KUYKENDALL, R. S. 1938. The Hawaiian Kingdom, 1778-1854. Honolulu: University of Hawaii Press.

MOREIRA, Ildeu de Castro; MASSARANI, Luisa \& ARANHA, Jayme. 2008. "Roquette-Pinto e a Divulgação Científica". In: Nísia Trindade Lima \& Dominichi Miranda de Sá (orgs.), Antropologia Brasiliana. Ciência e educação na obra de Edgard Roquette-Pinto. Belo Horizonte: Editora UFMG.

O'HANLON, Michael \& WELSCH, Robert (eds.). 2000. Hunting the gatherers. Ethnographic collectors, agents and agency in Melanesia, 1870-1930. New York: Berghahn Books.

ROQUETTE-PINTO, Edgard. 1923. "Um manto real do Hawai". Boletim do Museu Nacional, 1. 1927. Seixos Rolados. Estudos brasileiros. Rio de Janeiro: Mendonça, Machado \& C.

SANTOS, Rita de Cássia Melo. 2019. "Um antropólogo no museu: Edgard Roquette-Pinto e o exercício da antropologia no Brasil das primeiras décadas do século XX". Horizontes Antropológicos, 25 (53):283-315. . 2020. No coração do Brasil: A expedição de Edgard Roquette-Pinto à Serra do Norte (1912). Rio de Janeiro: SEE/Museu Nacional/UFRJ.

SEÇÃO DE MUSEOLOGIA. 2006. Relatório da Exposição de Longa Duração Culturas do Pacífico. Rio de Janeiro: Museu Nacional/UFRJ.

SEREJO, Cristiana (ed.). 2020. National Museum: overview of the Collections: Past, present and future. Rio de Janeiro: Museu Nacional, Universidade Federal do Rio de Janeiro. 
THOMAS, Nicholas. 1991. Entangled Objects. Exchange, Material culture and colonialism in the Pacific. London: Harvard University Press. . 1995. Oceanic art. London: Thames \& Hudson Ltd. . 2010. Islanders. The Pacific in the age of Empire. London: Yale University Press.

THOMAS, Nicholas; ADAMS, Julie; LYTHBERG, Billie; NUKU, Maia \& SALMOND, Amiria (eds.). 2016. Artefacts of Encounter. Cook's voyages, colonial collecting and museum histories. Honolulu: University of Hawaii Press.

VELOSO JUNIOR, Crenivaldo Regis. 2019. "Índice de objetos, índice de Histórias: o Catálogo Geral das Coleções de Antropologia e Etnografia do Museu Nacional". Ventilando Acervos, 1:71-89.

WALTERS, Mark Jerome. 2006. Seeking the sacred raven. Politics and extinction on a Hawaiian island. London: Shearwater Books. 